\title{
PREAURICULAR SINUS: INCIDENCE AND INHERITANCE
}

George St. Stoyanov', Alice Renjilian², Boyko Matev², Magdalena Bliznakova², Velizar Gaydardzhiev ${ }^{3}$, Mariya Levkova ${ }^{4}$, Dimitrichka Bliznakova ${ }^{5}$, Kameliya Bratoeva ${ }^{6}$, Anton Tonchev ${ }^{7}$, Nikolay Sapundzhiev ${ }^{8}$

${ }^{1}$ Department of General and Clinical Pathology, Forensic Medicine and Deontology, Faculty of Medicine, Medical University of Varna

${ }^{2}$ Student, Faculty of Medicine, Medical University of Varna

${ }^{3}$ Student, Faculty of Dental Medicine, Medical University of Varna

${ }^{4}$ Department of Medical Genetics, Faculty of Medicine, Medical University of Varna

${ }^{5}$ Medical College, Medical University of Varna

${ }^{6}$ Department of Physiology and Pathophysiology, Faculty of Medicine, Medical University of Varna

${ }^{7}$ Department of Anatomy and Cell Biology, Faculty of Medicine, Medical University of Varna

${ }^{8}$ Department of Neurosurgery and ENT Diseases, Faculty of Medicine, Medical University of Varna

\section{ABSTRACT}

INTRODUCTION: The preauricular sinus (PAuS) is a malformation of the auricula pinna. The structure may present isolated or as a component of a number of oto-renal syndromes.

AIM: The aim of this study was to establish the incidence of PAuS in a Bulgarian cohort and propose a model for its inheritance, based on the transgenerational mechanisms derived from the genealogic trees of interviewed individuals.

MATERIALS AND METHODS: A total of 100 healthy individuals were prospectively evaluated for the presence of a PAuS on a random cohort sampling principle. A descriptive statistical approach was used when categorizing the individual features. Individuals were also assessed in terms of their genealogies and presence of renal symptoms.

RESULTS: Of all assessed individuals, $3 \%(n=3)$ had a structure complying with the criteria for a PAuS. No one having the structure reported renal symptoms. The genealogical trees were characteristic of a dominant trait with incomplete penetrance.

Address for correspondence:

George St. Stoyanov

Faculty of Medicine

Medical University of Varna

55 Marin Drinov St

9002 Varna

e-mail:georgi.geesh@gmail.com

Received: November 27, 2018

Accepted: December 12, 2018
CONCLUSION: The incidence of PAuS in our study cohort is similar to that of other Caucasian cohorts and gives a rare modern glimpse into the transgenerational inheritance of the PAuS, together with data on the oto-nephrological syndromes.

Keywords: preauricular sinus, incidence, inheritance, genealogy 


\section{INTRODUCTION}

The auricular pinna has a very complex embryological formation and migration patterns to its definitive place. A number of factors may cause malfusion, abnormal migration or incomplete formation of certain structures $(1,2)$. These may result in a number of defects ranging from a complete absence of an auricle to minor defects, some even considered cosmetic as they do not interfere with the normal function of the external year (3-5). A diverse range of auricular deformities has been included in the diagnostic spectrum of a number of conditions, related to inherited genetic syndromes (5-7).

The preauricular sinus (PAuS), known in the past as fistula auricularis congenital and natural earring holes, is a variable congenital malformation, first described in 1864 by C.F. Heusinger and later in the same year by R. Virchow $(8,9)$. It originates as a result of a defect in the development and fusion of the second pharyngeal arch and is characterized as a bilateral or unilateral, preexisting foramen, dent or a dimple most commonly located on the crus of the auricular helix (10-12). Rarely, however, similar structures can be located in other areas of the auricle such as the tragus, pinna, etc. due to the complexity of auricular formation (13-15).

The structure can often become inflamed and garners an interest mainly for ENT specialists, pediatricians and neurologists, due to the specifics of its location, recurrence after treatment, main age group of complications, caused by the structure and specifics of the anatomy of the facial nerve, other nearby structures and their potential damage (10-12,16-19).

However, as a structure identified as a part of a number of inherited syndromes, such as the Beckwith-Wiedemann syndrome, Lachiewicz-Sibley and the brachio-oto-renal syndrome also known as Melnik-Fraser, there is very little modern evidence and information on the mechanisms of the individual transgenerational inheritance or lack thereof for PAuS (6,7,11,13,20-22). Most of the research in the field, especially in the genetic and genealogical aspects, had been carried out prior to the 1950s and, to our knowledge, no similar studies have been carried out ever since (23-29).

Furthermore, there is a great variety in the incidence of occurrences of PAuS in different geograph- ical cohorts, further increasing the interest in this variable inheritable structure $(11,20)$.

\section{AIM}

The aim of this study was to establish the incidence of PAuS in a Bulgarian cohort and propose a model for its inheritance, based on the transgenerational mechanisms derived from the genealogic trees of interviewed individuals.

\section{MATERIALS AND METHODS}

The study was carried out in accordance with the ethical standards of the Helsinki Declaration of 1975, as revised in 2008 and those of the Bulgarian Ministry of Healthcare.

The study design was agreed upon by all authors and carried out prospectively in the period February - March 2017 at Medical University - Varna "Prof. Dr. Paraskev Stoyanov", Varna, Bulgaria. Only healthy out-hospital individuals were considered for evaluation on a random cohort sampling principle. A descriptive statistical approach was used when categorizing the individual features of participants for data sampling. Informed consent was obtained from all assessed individuals.

A structure was considered a PAuS when present in the region of the crus of the auricular helix as a preexisting dent, dimple or foramen, not due to an ear piercing, other cosmetic or medical procedures. The set criteria were virtually identical to similar studies of the structure, carried out in other cohorts $(10-12,22)$.

If presenting with a PAuS, individuals were specifically assessed in regard to their family history and the distribution of a PAuS amongst their direct relatives, without the family members being included into the descriptive statistical analysis of incidence, with the aim of evading blurring of the cohort structure by including the whole family tree of individuals with PAuS.

\section{RESULTS}

A total of 100 otherwise healthy, outpatient individuals, of which 51 males and 49 females, with a total mean age of 26.87 years of age, standard deviation \pm 12.53 , median age of 21 years and a range of 50 years (minimal age 19 years and maximal 69 years) 
were specifically assessed for the presence of a PAuS by a single author.

Of all assessed individuals, 3\% $(n=3)$ had a structure that complied with the set criteria for a PAuS, with $1 \%(\mathrm{n}=1)$ having a left-sided PAuS, $1 \%$ $(n=1)$ having a right-sided PAuS and $1 \%(n=1)$ having a bilateral PAuS (Fig. 1). No correlation between the presence of the structure and the age of the assessed individuals could be determined. However, two of the three identified individuals with the structure were male.

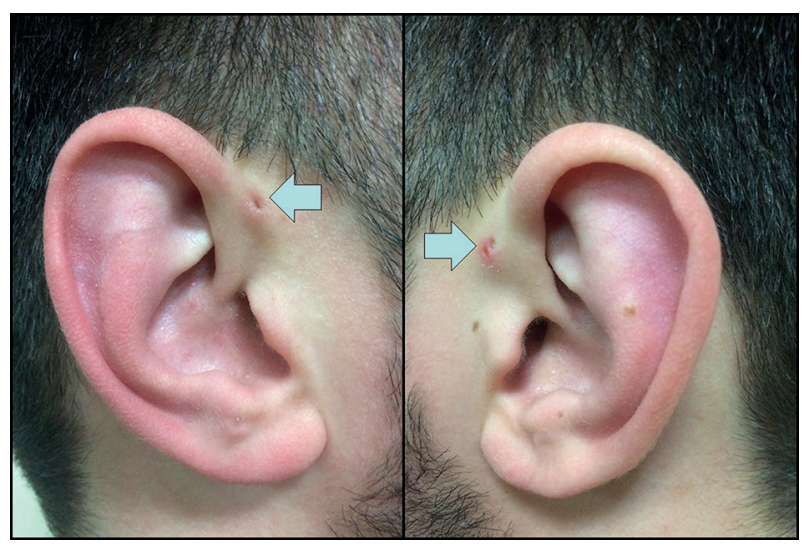

Fig. 1. Bilateral case of PAuS (arrows)

The genealogy of the first case of a left-sided unilateral PAuS, a 20 -year-old male, could not be established because the individual was adopted and had no information about his biological parents.

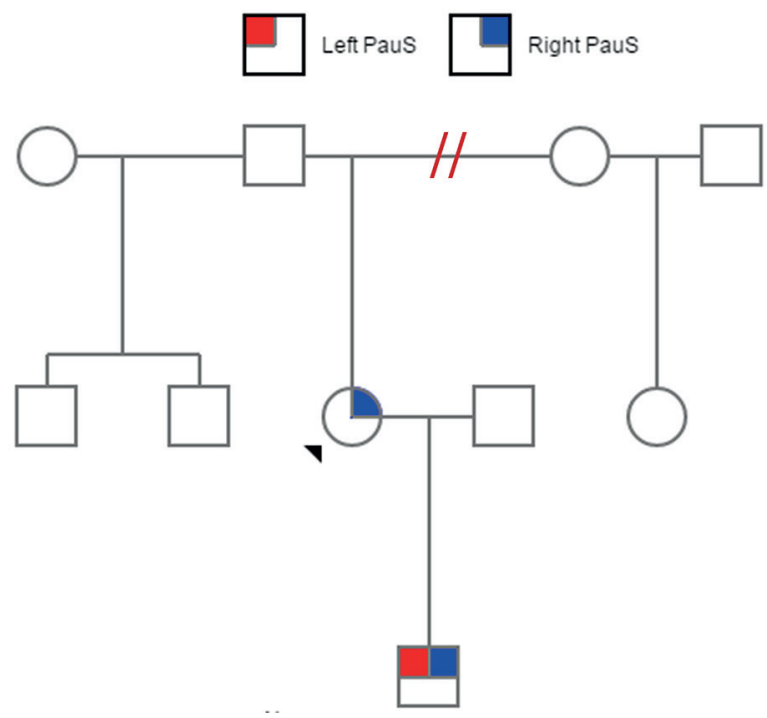

Fig. 2. Pedigree of the second case
The second case, a 32-year-old female with a right-sided unilateral PAuS, had a genealogic tree with a half-sister from the same mother and two half-brothers from the same father, none of whom had a PAuS. She, however, had a son, with a bilateral PAuS (Fig. 2).

The third case, a 20 -year-old male with a bilateral PAuS, however, had a clear family history of relatives with a PAuS and a genealogic tree including both bilateral and unilateral cases and twins of different gender having a unilateral PAuS on different ears (Fig. 3).

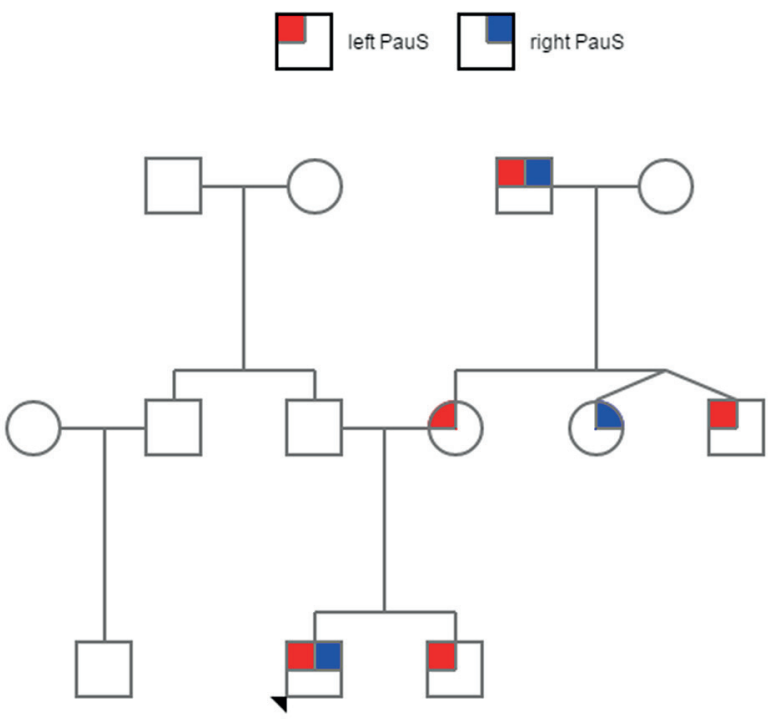

Fig. 3. Pedigree of the third case

The interviewed individuals were specifically assessed for renal malformations and problems, with none of them, including relatives with a PAuS, reporting any such symptoms.

Based both on the sample cohort and the genealogic trees of the two cases that allowed for this type of investigation the PAuS is more commonly found on the left ear, followed by bilateral expression and is least common as a unilateral finding on the right ear.

\section{DISCUSSION}

With no specific statement in scientific literature that a PAuS necessitates the presence of the otorenal syndromes, our study, to our knowledge, is the first to describe a lack of a conditio sine non qua for the two. Both ontological and renal manifestations of these syndromes are probably a result of a genetic 
factor affecting the stages of pharyngeal arch fusion and the early stages of renal formation, meaning the process takes place at a certain embryological stage, not at certain locations. An isolated PAuS is by no means a predisposition for an oto-renal syndrome, however, as a diagnostic criteria it requires such individuals to be assessed for them.

The genealogic trees give some rare modern insight into the inheritance of PAuS as an individual malformation $(26,29,30)$. The fact that the structure is passed from parent to child and does not skip generations establishes it as a dominant trait. However, the fact that parents without a PAuS can have a child with a PAuS establish its dominance either as incomplete, dependent on other genetic factors or as a nongenetic phenomenon dependent of external factors.

The mechanism of unilateral to bilateral and bilateral to unilateral inheritance, together with the possibility of left-sided and right-sided unilateral expression in siblings and twins, gives this supposed inherited malformation a multifactual inheritance state, as a single genetic factor could not establish such a complex model of inheritance.

The reported incidence figures in our study are similar to others reported in European and Caucasian populations, somewhat underlining the genetic predispositions on inheritance, as the reported figures in Asian and African populations are significantly higher $(11,14,20,22)$.

The establishment of a modern model of inheritance that confirms the results of studies published more than half a century ago and not carried out since is another valuable aspect of our study as it proves the results of those studies reproducible and the genealogical aspects valid.

Even so, more research should be carried out in the field of PAuS inheritance as an individual malformation in order to provide the chromosomal basis of this considerably rare malformation, or conversely if there is no genetic basis to establish the environmental factors leading to auricular embryological mal-fusion.

Nonetheless, the presence of such wide differences between incidence in different populations and possible variants of transgenerational inheritance garner an interest for future research and ample scope for in-depth genetical analysis to estab- lish the factor or lack thereof for left-to-right inheritance, association with well-established syndromes and the possible presence of different genotypes leading to the same phenotype. On the other hand, some environmental factors for malfusion may also be discussed.

\section{CONCLUSION}

The incidence of the PAuS in our study cohort is similar to that of other Caucasian cohorts, however, while other studies state an even distribution between genders and left and right sided location, our findings state that the PAuS is more often found in males as a left-sided unilateral structure. Furthermore, the mechanism of inheritance garners an increased interest to the structure as it shows a multifactorial nature of inheritance. As a component of some rare genetic syndromes, further studies on this type of individual inheritance of the structure should be encouraged.

\section{Acknowledgements:}

The authors would like to thank Associate Professor Trifon Chervenkov, MD, PhD for contributions on defining the possible mechanisms of inheritance of the structure.

\section{Disclosures:}

Preliminary results were presented in part at the Fifth Annual Black Sea Symposium for Young Scientist in Biomedicine: 6-9 April 2017, Varna, Bulgaria

\section{Financial Support:}

This research received no specific grant from any funding agency, commercial or not-for-profit organization.

\section{Ethical standards:}

The authors assert that all procedures contributing to this work comply with the ethical standards of the relevant national and institutional guidelines on human experimentation (Medical University of Varna) and with the Helsinki Declaration of 1975, as revised in 2008 .

\section{REFERENCES}

1. Wood-Jones F, I-Chuan W. The development of the external ear. J Anat. 1934;68(Pt 4):525-33.

2. Kim JR, Kim DH, Kong SK, Gu PM, Hong TU, Kim BJ, et al. Congenital periauricular fistulas: Possible variants of the preauricular sinus. Int J Pe- 
George St. Stoyanov, Alice Renjilian, Boyko Matev et al.

diatr Otorhinolaryngol. 2014;78(11):1843-8. doi: 10.1016/j.ijporl.2014.08.005.

3. Kugelman A, Hadad B, Ben-David J, Podoshin L, Borochowitz Z, Bader D. Preauricular tags and pits in the newborn: the role of hearing tests. Acta Paediatr. 1997;86(2):170-2.

4. Mohammadi AA, Imani MT, Kardeh S, Karami MM, Kherad M. Non-surgical management of congenital auricular deformities. World J Plast Surg. 2016;5(2):139-47.

5. Kanamori G, Witter M, Brown J, WilliamsSmith L. Otolaryngologic manifestations of Down syndrome. Otolaryngol Clin North Am. 2000;33(6):1285-92.

6. Kochhar A, Fischer SM, Kimberling WJ, Smith RJ. Branchio-oto-renal syndrome. Am J Med Genet A. 2007;143A(14):1671-8. doi: 10.1002/ajmg.a.31561.

7. Elliott M, Bayly R, Cole T, Temple IK, Maher ER. Clinical features and natural history of BeckwithWiedemann syndrome: presentation of 74 new cases. Clin Genet. 2008;46(2):168-74.

8. Heusinger CF. Hals-Kiemen-Fisteln von noch nicht beobachteter Form. Arch fur Pathol Anat und Physiol und fur Klin Med. 1864;29:358-80.

9. Virchow R. Ueber Missbildungen am Ohr und im Bereiche des ersten Kiemenbogens. Arch fur Pathol Anat und Physiol und fur Klin Med. 1864;30:221-34.

10. Tan T, Constantinides H, Mitchell TE. The preauricular sinus: A review of its aetiology, clinical presentation and management. Int J Pediatr Otorhinolaryngol. 2005;69(11):1469-74. doi: 10.1016/j. ijporl.2005.07.008.

11. Kumar Chowdary KV, Sateesh Chandra N, Karthik Madesh R. Preauricular sinus: A novel approach. Indian J Otolaryngol Head Neck Surg. 2013;65(3):234-6. doi: 10.1007/s12070-012-0520-y.

12. Scheinfeld NS, Silverberg NB, Weinberg JM, Nozad V. The preauricular sinus: A review of its clinical presentation, treatment, and associations. Pediatr Dermatol. 2004;21(3):191-6. doi: 10.1111/j.0736-8046.2004.21301.x.

13. Rataiczak H, Lavin J, Levy M, Bedwell J, Preciado D, Reilly BK. Association of recurrence of infected congenital preauricular cysts following incision and drainage vs fine-needle aspiration or antibiotic treatment. JAMA Otolaryngol Neck Surg. 2017;143(2):131-4. doi: 10.1001/jamaoto.2016.2988.
14. Choi SJ, Choung Y-H, Park K, Bae J, Park HY. The variant type of preauricular sinus: postauricular sinus. Laryngoscope. 2007;117(10):1798-802. doi: 10.1097/MLG.0b013e3180caalca.

15. Kim HJ, Lee JH, Cho HS, Moon IS. A case of bilateral postauricular sinuses. Korean J Audiol. 2012;16(2):99-101. doi: 10.7874/kja.2012.16.2.99.

16. Yu CV, Khera KD, Pauwels J, Chadha NK. Prevalence and ethnic variation of pre-auricular sinuses in children. Int J Pediatr Otorhinolaryngol. 2016;80:43-8. doi: 10.1016/j.ijporl.2015.11.008.

17. Gan EC, Anicete R, Tan HKK, Balakrishnan A. Preauricular sinuses in the pediatric population: Techniques and recurrence rates. Int J Pediatr Otorhinolaryngol. 2013;77(3):372-8. doi: 10.1016/j. ijporl.2012.11.029.

18. Choo OS, Kim T, Jang JH, Choung YH. The clinical efficacy of early intervention for infected preauricular sinus. Int J Pediatr Otorhinolaryngol. 2017;95:45-50. doi: 10.1016/j.ijporl.2017.01.037.

19. Prasad S, Grundfast K, Milmoe G. Management of congenital preauricular pit and sinus tract in children. Laryngoscope. 1990;100(3):320-1. doi: 10.1288/00005537-199003000-00021.

20. An SY, Choi HG, Lee JS, Kim JH, Yoo SW, Park B. Analysis of incidence and genetic predisposition of preauricular sinus. Int J Pediatr Otorhinolaryngol. 2014;78(12):2255-7. doi: 10.1016/j.ijporl.2014.10.027.

21. Wildervanck LS. Hereditary malformations of the ear in three generations: Marginal pits, pre-auricular appendages, malformations of the auricle and conductive deafness. Acta Otolaryngol. 1962;54(1-6):553-60.

22. Lee KY, Woo S, Kim SW, Yang J-E, Cho Y-S. The prevalence of preauricular sinus and associated factors in a nationwide population-based survey of South Korea. Otol Neurotol. 2014;35(10):1835-8. doi: 10.1097/MAO.0000000000000587.

23. Quelprud T. Ear pit and its inheritance. J Hered. 1940;31(9):379-84. doi: 10.1093/oxfordjournals. jhered.a104934.

24. Donald GF. Fistula auris congenita. Australas J Dermatol. 1952;1(4):253-5.

25. Ewing MR. Congenital sinuses of the external ear. J Laryngol Otol. 1946;61(1):18-23.

26. Edmonds HW, Keeler CE. Natural “ear-ring” holes. J Hered. 1940;31(12):507-10. doi: 10.1093/oxfordjournals.jhered.a104828. 
27. Whitney DD. Three generations of ear pits. J Hered. 1939;30(8):323-4. doi: 10.1093/oxfordjournals.jhered.a104753.

28. Kindred JE. Inheritance of a pit in the skin of the left ear. J Hered. 1921;12(8):366-7. doi: 10.1093/oxfordjournals.jhered.a102125.
29. Connon FE. The inheritance of ear pits in six generations of a family. J Hered. 1941;32(11):413-6. doi: 10.1093/oxfordjournals.jhered.a104980.

30. McDonough ES. On the inheritance of ear pit. J Hered. 1941;32(5):169-70. doi: 10.1093/oxfordjournals.jhered.a105028. 